\title{
Comparison of geometrical isomerization of unsaturated fatty acids in selected commercially refined oils
}

\author{
By M. Tasan, ${ }^{*}$ U. Gecgel and M. Demirci
}

\author{
Department of Food Engineering, Agricultural Faculty, Namik Kemal University, \\ TR-59030, Tekirdag, Turkey \\ ( ${ }^{\star}$ Corresponding author: e-mail: mtasan@nku.edu.tr)
}

\begin{abstract}
RESUMEN
Comparación de isómeros geométricos de ácidos grasos insaturados en aceites refinados comerciales seleccionados.
\end{abstract}

Cuatro aceites vegetales refinados comerciales diferentes fueron analizados por cromatografía de gases para determinar el contenido en ácidos grasos trans. Los resultados obtenidos mostraron que el contenido total de los FA trans de aceites refinados de girasol, maíz, soja y avellana fueron $0.68 \pm 0.41,0.51 \pm 0.24,1.27 \pm 0.57$, y $0.26 \pm 0.07 \%$ de FA totales, respetivamente. Los ácidos grasos totales trans comprenden a isómeros de FA C18:1, C18:2 y C18:3. Cinco marcas de aceites de girasol refinado y dos marcas de aceite de avellana contenían cantidades no medibles de ácidos trans C18:3 totales. Los ácidos C18:2 trans totales fueron los FA trans predominantes en el aceite de girasol y maíz refinado, mientras los FA poliinsaturados trans fueron encontrados a niveles altos en el aceite de soja refinado. Sin embargo, los ácidos trans $\mathrm{C} 18: 1$ totales fueron los principales FA trans en el aceite de avellana refinado. Los aceites vegetales refinados comerciales con un contenido relativamente alto de FA poliinsaturado total contenían cantidades considerable de isómeros poliinsaturados trans. Este estudio indica que es necesario optimizar la industria de desodorización, especialmente el tiempo y la temperatura, para cada composición diferente de FA del aceite usado.

PALABRAS CLAVE: Aceite vegetal refinado-Desodorización - Grado de isomerización - Isómeros trans.

\section{SUMMARY}

Comparison of geometrical isomerization of unsaturated fatty acids in selected commercially refined oils.

Four different commercially refined vegetable oils were analyzed by capillary gas-liquid chromatography for their trans fatty acid contents. The results obtained showed that the total trans FA contents in refined sunflower, corn, soybean, and hazelnut oils were $0.68 \pm 0.41,0.51 \pm 0.24$, $1.27 \pm 0.57$, and $0.26 \pm 0.07 \%$ of total FA, respectively. The total trans FA comprised isomers of the C18:1, C18:2 and C18:3 FA. Meanwhile, five brands of the refined sunflower oil and two brands of hazelnut oil contained no measurable amounts of total trans C18:3 acids. The total trans C18:2 acid was the predominant trans FA found in the refined sunflower and corn oils, while trans polyunsaturated FAs for the refined soybean oils were found at high levels. However, total trans C18:1 acid was the major trans FA for refined hazelnut oils. The commercially refined vegetable oils with a relatively high total polyunsaturated FA contained considerable amounts of trans polyunsaturated isomers. This study indicates that it is necessary to optimize industrial deodorization, especially the time and temperature, for each different FA composition of oil used.

KEY-WORDS: Degree of isomerization - Deodorization trans Isomer - Refined vegetable oil.

\section{INTRODUCTION}

The influence of dietary fats/oils on human health and nutrition is related to the quantity of fats/oils consumed, fatty acid (FA) compositions, and the bioactive micronutrients present (Mayamol et al., 2004). Vegetable oils constitute an indispensable part of the human diet and their consumption has been steadily increasing worldwide while that of animal fats has decreased. Vegetable oils intended for normal consumption are refined (Schwarz, 2000). Most consumers use refined oils. On the other hand, consumer interest for minimally processed products has increased. Thus, the use of cold pressed vegetable oils has increased significantly during the last decades (Matthaus and Bruhl, 2003).

The objective of refining oils is to remove unacceptable materials with the least possible effect on desirable components and the least possible loss in the quantity of the oil (Jawad et al., 1983). On the other hand, chemical or physical refining subjects the oil to high temperatures, alkali and metal processing equipment that can alter their chemical composition (Karaali, 1985). The typical oil refining process includes degumming, chemical or physical refining, bleaching and deodorization (Erickson, 1995). Each refining step has a specific function for removing certain minor components, which can act as prooxidants or antioxidants (Jung et al., 1989). In the refining process, vegetable oils are commonly heated to between 60 and $100^{\circ} \mathrm{C}$ before deodorization. During the deodorization stage, the temperature is increased to $180-270^{\circ} \mathrm{C}$ (Martin et al., 2007). The deodorization stage is a principal step in the vegetable oil refining process. Free fatty acids, aldehydes, unsaturated hydrocarbons and ketones, which cause undesirable odors and flavors in the oil, 
are eliminated during this stage (Zehnder, 1995). However, the high temperature used in this stage may induce the geometrical isomerization of unsaturated FA, such as C18:2 and C18:3 (Tasan and Demirci, 2003). During this stage, other factors which also affect the formation of trans FA include heating time, pressure and stripping steam dosage (Wolff, 1993; Bruggen et al., 1998; Martin et al., 2008). The rate of conversion also depends on the level of unsaturation of the FA molecule (Bruggen et al., 1998). On the other hand, trans FA isomers that may be formed in vegetable oils during refining are quite different in type and level from those formed during the hydrogenation process (Ackman et al., 1974). Whereas in hydrogenated oils/fats the analytical focus is mainly on the monoenoic cis and trans $\mathrm{FA}$, isomers formed during deodorization are mostly dienoic and trienoic mono-trans FA (Duchateau et al., 1996).

Knowledge about the trans FA content of fats and oils is important not only for the manufacturer as an aid in processing optimization but also for health authorities due to the fact that the potential health hazards of trans FA intake are well known (Ferrari et al., 1996). Although refined vegetable oils make almost the lowest contribution to the total trans FA intake in the diet, they contain trans polyunsaturated FA formed in small amounts during refining, mainly during the deodorization stage. In addition, because of their high consumption, i.e., in the Mediterranean countries, evaluation of the trans FA contents in refined vegetable oils becomes important. In accordance with nutritionists' proposals, there is a strong tendency in the vegetable oil industry to keep the trans FA contents of vegetable oils as low as possible (Kemeny et al., 2001). On the other hand, the US Food and Drug Administration (FDA, 2003) has issued the rule requiring manufacturers to include trans FA or trans fat on the nutrition facts label. Therefore, there has been much effort on the part of the vegetable oil industry to meet the labeling requirement. From these perspectives, the aim of the present work was to gather an overview of the FA compositions with special emphasis on the trans FA of commercially refined oils of different botanical origins. Such data can also present details on the variability in trans FA content within a group of refined vegetable oil products. In addition, the trans FA contents of the analyzed oils were compared and discussed with respect to their formation.

\section{MATERIALS AND METHODS}

\subsection{Standards and reagents}

FA methyl ester (FAME) standards (99\% purity) were provided by Nu-Check-Prep Inc. (Elysian, MN). All chemicals were of analytical or chromatographic grade.

\subsection{Sample selection}

The most commonly marketed brands of the refined vegetable oils in Turkey were purchased from several local supermarkets and immediately analyzed. The samples were selected from the most popular commercially refined vegetable oils, namely refined sunflowerseed oil, refined corn oil, refined soybean oil and refined hazelnut oil. These oils were produced by industrial manufacturers which are major producers of the refined vegetable oils in all regions of Turkey. Three samples from each brand were taken over a 9-month period. The samples of refined sunflower, corn, soybean and hazelnut oils were evaluated in 30, 18, 15 and 9 brand groups, respectively. The samples were stored at $4^{\circ} \mathrm{C}$ until analyzed. Data were given as arithmetic means \pm standard deviation (SD) for each group of the refined vegetable oils unless otherwise indicated.

\subsection{Preparation of FAMEs}

FAMEs were prepared according to the American Oil Chemists Society (AOCS, 1992) official method Ce 2-66. The FAMEs were obtained from the lipid fractions after alkaline hydrolysis, followed by methylation in methanol with $12.5 \%$ boron trifluoride catalyst. The final concentration of the FAMEs was approximately $7 \mathrm{mg} / \mathrm{mL}$ in heptane.

\subsection{Capillary gas-liquid chromatography (GLC) analyses of FAMEs}

Analyses of the FAMEs by capillary GLC were carried out on a Hewlett-Packard 6890 chromatograph (Hewlett-Packard, Wilmington, DE) equipped with a Chrompack Autosampler-M911 (Chrompack, Middelburg, the Netherlands) for split-type injection and a flame-ionization detector. A fused-silica capillary column (Chrompack) was used for the FAME analysis: CP-Sil 88, $100 \mathrm{~m} \times 0.25 \mathrm{~mm}$ i.d., $0.20 \mu \mathrm{m}$ film thickness. GLC operating conditions were: a temperature program of $130^{\circ} \mathrm{C}$ for $5 \mathrm{~min}$ increasing at a rate of $2^{\circ} \mathrm{C} / \mathrm{min}$ to $177^{\circ} \mathrm{C}$; injector temperature, $200^{\circ} \mathrm{C}$; detector temperature, $250^{\circ} \mathrm{C}$; carrier gas, helium at a flow rate of $1 \mathrm{~mL} / \mathrm{min}$; split ratio 1:100; and volume of injected sample $1 \mu \mathrm{L}$. The peaks were tentatively identified by comparing the retention times and area percentages with those of authentic standards of FAMEs obtained from Nu-Chek-Prep Inc. (Elysian, MN) and on the basis of literature data for trans FA (Wolff, 1992; Duchateau et al., 1996). The final results were expressed as relative percentage of individual FA.

\subsection{Statistical data analysis}

Differences in the mean values of each FA, total trans polyunsaturated FA, and total trans FA contents were tested by analysis of variance using an SPSS software program (SPSS Inc., Chicago, IL), and the 
significance of differences among the mean values was determined using the Duncan's multiple range tests.

\section{RESULTS AND DISCUSSION}

A comparison of trans FA contents (mean \pm $\mathrm{SD}, \%$ of total $\mathrm{FA}$ ) from the commercially refined sunflower, corn, soybean, and hazelnut oils are presented in Table 1. The degrees of isomerization of the C18:1, C18:2 and C18:3 FA are also given in Table 1.

The $\mathrm{C} 16: 0$ and $\mathrm{C} 18: 0$ acids were the main saturated FA for all refined vegetable oils analyzed. The C16:0 acid contents obtained for refined corn and soybean oils were significantly higher $(P<$ 0.01 ) than those of the others. For the C18:0 acid, the refined soybean oils exhibited a significantly higher mean value $(P<0.01)$ than the others did. The main monounsaturated $\mathrm{FA}$, the total $\mathrm{C} 18: 1$ acid, ranged from $29.13 \pm 0.95$ and $80.90 \pm 0.99 \%$ in all groups of the refined vegetable oils and the mean value obtained for refined hazelnut oil was significantly higher $(P<0.01)$ than those obtained for the others. Among the polyunsaturated FA, the total C18:2 acid levels ranged from 10.01 \pm 0.70 and $59.29 \pm 3.03 \%$ in all groups of the refined vegetable oils, with significantly higher mean values $(P<0.01)$ observed for refined sunflower and corn oils in comparison with the others. As for the total C18:3 acids, their low levels (approximately 0.10\%) for refined sunflower and hazelnut oils were statistically similar $(P>0.01)$. In contrast, the mean values of the total $\mathrm{C} 18: 3$ acid in the refined corn oils were $0.78 \pm 0.10 \%$, whereas those of refined soybean oils were $7.10 \pm 0.53 \%$. The sum of six minor FA (C14:0, C16:1, C20:0, C20:1, C22:0, C24:0), and unidentified FA were below $2 \%$ of total FA. All obtained FA profiles were within the ranges found in the literature.

As illustrated in Table 1, there was a remarkable variation in the amounts of the total trans FA among the different refined vegetable oils. The mean values of total trans FA varied from $0.26 \pm 0.07$ to $1.27 \pm 0.57 \%$ of total FA for all refined vegetable oils $(P<0.01)$. The total trans FA comprised isomers of the C18:1, C18:2 and C18:3 acids. Meanwhile, five brands of refined sunflower oil and two brands of hazelnut oil contained no measurable amounts of the total trans C18:3 acid. All samples studied contained total trans C18:1 acid and total trans C18:2 acid. The refined soybean oils had higher total trans FA content than the others. In addition, similar results were observed for the total trans polyunsaturated FA in all groups of refined vegetable oils, which varied from $0.09 \pm 0.01$ to $1.21 \pm 0.55 \%$ of total FA $(P<0.01)$. A lower mean value was obtained for refined hazelnut oil. Thus, the highest difference between the total trans FA and the total trans polyunsaturated FA contents was found in this type of oil. Wolff (1992) and Kellens (1997) reported that the trans FA contents for refined soybean oils were 0.16-2.99 and 0.9$3.5 \%$, respectively. Ferrari et al. (1996) reported that the total trans FA contents of refined corn, soybean and rapeseed oils were 1.5, 4.6, and $2.4 \%$, respectively. De Greyt et al. (1996) expressed that the total trans FA contents of the commercial sunflower, peanut, corn and soybean oils ranged from 0.1 to $4.6 \%$. Medina-Juarez et al. (2000) found that trans FA contents in refined vegetable oils varied from 0.90 to $2.93 \%$. Tasan and Demirci (2003) revealed that the concentration of total trans FA in physically refined sunflower oil (2.56 \pm $0.25 \%$ ) was higher than in chemically refined sunflower oil $(0.76 \pm 0.27 \%)$. Van Hoed et al. (2006) demonstrated that the high temperature of the deodorization process led to the formation of trans isomers, resulting in $0.8 \%$ of trans FA in fully refined rice bran oil. García et al. (2006) revealed that the content of total trans FA in refined safflower oil with high oleic acid was $0.34 \%$ of the total FA. Martin et al. (2008) reported that the mean trans FA levels ranged from 0.8 and $2.6 \%$ for refined soybean oils.

The total trans C18:1 monounsaturated FA was the predominant trans FA found in refined hazelnut oil, with a mean value of $0.17 \pm 0.05 \%$. A higher mean value of total trans C18:1 acid was obtained for refined hazelnut oil than those obtained for the other oils, with mean values lower than $0.1 \%$. For trans polyunsaturated FA, the total trans $\mathrm{C} 18: 2$ acid was the predominant trans FA found in the refined sunflower and corn oils, while trans polyunsaturated FA for the refined soybean oil was found at high levels. Refined hazelnut oil exhibited a considerably lower mean value for total trans $\mathrm{C} 18: 2$ acid than the other refined oils. Meanwhile, the mean values of the total trans C18:1 and total trans C18:2 acids in refined corn oil were very similar. The low mean values of total trans $\mathrm{C} 18: 3$ acid were detected in the refined vegetable oils, which varied from $0.01 \pm 0.01$ to $0.07 \pm 0.03 \%$, except for soybean oil, whose mean value was $0.71 \pm 0.28 \%$. The differences among the refined vegetable oils for both the total trans C18:1 acid and the total trans C18:2 acid, except for refined hazelnut oil, were not statistically significant $(P>0.01)$. As for total trans $C 18: 3$ acid, no significant differences $(P>0.01)$ existed among total trans C18:3 acid of the refined vegetable oils, except for refined soybean oil. The distribution of the C18:1, C18:2, and C18:3 acids in the starting vegetable oils is quite different. Consequently, the amounts of detectable trans FA formed during refining are different (Bruggen et al., 1998). Also, fluctuations in the conditions of industrial processing such as temperature, duration, vacuum, humidity, stripping steam dosage and different sample origin can cause variations in trans polyunsaturated FA concentrations (Tasan and Demirci, 2003; Martin et al., 2008).

Taking into account all the available data (Table 1), the degrees of isomerization of the C18:1, C18:2 and C18:3 acids generally showed a wide variation within each group of refined 
Table 1

Trans FA contents and degree of isomerization in the commercially refined vegetable oils.

\begin{tabular}{|c|c|c|c|c|}
\hline Fatty acids ${ }^{1}$ & $\begin{array}{l}\text { Sunflower oils } \\
\qquad(n=30)^{6}\end{array}$ & $\begin{array}{l}\text { Hazelnut oils } \\
\quad(n=9)\end{array}$ & $\begin{array}{l}\text { Corn oils } \\
(n=18)\end{array}$ & $\begin{array}{l}\text { Soybean oils } \\
\quad(n=15)\end{array}$ \\
\hline $16: 0$ & $5.83 \pm 0.20^{a}$ & $5.62 \pm 0.62^{a}$ & $10.74 \pm 0.31^{b}$ & $10.11 \pm 0.58^{b}$ \\
\hline $18: 0$ & $3.62 \pm 0.23^{c}$ & $2.47 \pm 0.20^{b}$ & $1.96 \pm 0.16^{a}$ & $4.13 \pm 0.18^{d}$ \\
\hline$\Sigma 18: 1$ trans $^{2}$ & $0.08 \pm 0.04^{a}$ & $0.17 \pm 0.05^{b}$ & $0.08 \pm 0.03^{a}$ & $0.06 \pm 0.02^{a}$ \\
\hline $18: 1 \mathrm{cis}$ & $29.27 \pm 3.23^{\mathrm{a}}$ & $80.73 \pm 1.02^{b}$ & $29.05 \pm 0.93^{\mathrm{a}}$ & $26.37 \pm 1.02^{\mathrm{a}}$ \\
\hline$\Sigma 18: 1$ & $29.35 \pm 3.22^{\mathrm{a}}$ & $80.90 \pm 0.99^{b}$ & $29.13 \pm 0.95^{\mathrm{a}}$ & $26.43 \pm 1.03^{\mathrm{a}}$ \\
\hline$\Sigma 18: 2$ trans $^{3}$ & $0.59 \pm 0.39^{b}$ & $0.08 \pm 0.02^{a}$ & $0.36 \pm 0.22^{b}$ & $0.50 \pm 0.29^{b}$ \\
\hline $18: 2$ cis & $58.70 \pm 2.84^{c}$ & $9.93 \pm 0.69^{\mathrm{a}}$ & $55.71 \pm 1.27^{c}$ & $49.80 \pm 1.70^{b}$ \\
\hline$\Sigma 18: 2$ & $59.29 \pm 3.03^{c}$ & $10.01 \pm 0.70^{a}$ & $56.07 \pm 1.21^{\mathrm{c}}$ & $50.30 \pm 1.62^{b}$ \\
\hline$\Sigma 18: 3$ trans $^{4}$ & $0.01 \pm 0.01^{a}$ & $0.01 \pm 0.01^{a}$ & $0.07 \pm 0.03^{a}$ & $0.71 \pm 0.28^{b}$ \\
\hline $18: 3 \mathrm{cis}$ & $0.09 \pm 0.03^{\mathrm{a}}$ & $0.08 \pm 0.01^{\mathrm{a}}$ & $0.78 \pm 0.10^{b}$ & $6.39 \pm 0.37^{\circ}$ \\
\hline$\Sigma 18: 3$ & $0.10 \pm 0.04^{\mathrm{a}}$ & $0.09 \pm 0.02^{a}$ & $0.85 \pm 0.11^{b}$ & $7.10 \pm 0.53^{c}$ \\
\hline Others $^{5}$ & $1.81 \pm 0.11^{c}$ & $0.91 \pm 0.06^{a}$ & $1.25 \pm 0.11^{b}$ & $1.93 \pm 0.08^{c}$ \\
\hline$\Sigma$ trans PUFA & $0.60 \pm 0.38^{\mathrm{bc}}$ & $0.09 \pm 0.03^{a}$ & $0.43 \pm 0.23^{b}$ & $1.21 \pm 0.55^{c}$ \\
\hline$\Sigma$ trans $\mathrm{FA}$ & $0.68 \pm 0.41^{\mathrm{ab}}$ & $0.26 \pm 0.07^{a}$ & $0.51 \pm 0.24^{a}$ & $1.27 \pm 0.57^{b}$ \\
\hline DI 18:1 & $0.27(0.06-0.59)^{7}$ & $0.21(0.15-0.23)$ & $0.28(0.17-0.43)$ & $0.23(0.12-0.34)$ \\
\hline DI 18:2 & $1.00(0.16-1.99)$ & $0.80(0.67-0.97)$ & $0.64(0.19-1.28)$ & $0.99(0.41-1.94)$ \\
\hline DI 18:3 & $10.00(0-30.0)$ & $11.11(0-18.18)$ & $8.24(4.69-13.25)$ & $10.00(4.67-13.18)$ \\
\hline Trans/cis & $0.78(0.15-1.58)$ & $0.29(0.22-0.36)$ & $0.59(0.21-1.03)$ & $1.41(0.65-2.53)$ \\
\hline
\end{tabular}

Data are the mean \pm standard deviation (SD), and are expressed as a weight percentage of total FA methyl esters. The means in each row with different letters (a-d) are significantly different $\left(\mathrm{P}<0.01\right.$, Duncan's multiple range test). ${ }^{1} \mathrm{FA}$ are designated by number of carbon atoms: number of double bonds. FA, fatty acid; PUFA, polyunsaturated FA. ${ }^{2}$ Constituted of $18: 1 \Delta 9$ trans. ${ }^{3}$ Sum of only $\Delta 9$ cis, $\Delta 12$ trans and $\Delta 9$ trans, $\Delta 12$ cis isomers for the $\mathrm{C} 18: 2 .{ }^{4}$ Sum of trans isomers were calculated as one group for the $\mathrm{C} 18: 3 .{ }^{5} \mathrm{Other}$ fatty acids include $14: 0,16: 1,20: 0,20: 1,22: 0,24: 0$, and unidentified fatty acids. ${ }^{6} \mathrm{n}$ = number of brands within group analyzed. ${ }^{7}$ Range (in parentheses). DI 18:1, degree of isomerization for the indicated fatty acid ratio of $\Sigma 18: 1$ trans on $\Sigma 18: 1$ times 100 . DI 18:2, degree of isomerization for the indicated fatty acid ratio of $\Sigma 18: 2$ trans on $\Sigma 18: 2$ times 100. DI 18:3, degree of isomerization for the indicated fatty acid ratio of $\Sigma 18: 3$ trans on $\Sigma 18: 3$ times 100 .

vegetable oils. In particular, refined sunflower oils showed a rather heterogeneous distribution of degree of isomerization for these unsaturated FA. This indicates that the operation conditions used during the deodorization stage could vary greatly from one producer to another. The degree of isomerization of unsaturated FA is an important indicator of the intensity of the thermal treatment applied to refined vegetable oil in the deodorization stage. Generally, isomerization is reported to begin at between 180 and $200^{\circ} \mathrm{C}$ and to increase with increasing temperature and prolonged heating time (De Greyt et al., 1996). A deodorization temperature of $220-230^{\circ} \mathrm{C}$ seems to be the critical point above which $\mathrm{C} 18: 3$ acid isomerization substantially increases. The critical temperature is higher for C18:2 acid, over $240^{\circ} \mathrm{C}$ (Henon et al., 1999). Kellens (1997) reported that chemical refining should be done at $230-235^{\circ} \mathrm{C}$ and physical refining at $235-240^{\circ} \mathrm{C}$ to obtain deodorized oils with low levels of trans FA (<1\%). Kemeny et al. (2001) found an increase in the relative percentage of isomerized C18:2 and C18:3 acids with an increase in either the deodorization time or the temperature. On the other hand, in this study, the mean values of the degree of isomerization of C18:3 acid were higher than those obtained for the C18:2 acid, while these values for C18:1 acid were found at very low levels for the groups of refined vegetable oils, as expected. De Greyt et al. (1996) reported that more C18:3 acid trans isomers are formed in soybean oil in spite of the fact that the initial level of C18:2 acid is higher. This phenomenon is described in the literature (Wolff 1992) and explained by the fact that the probability for a C18:3 molecule to be isomerized during heat treatment is about 10 to 12 times high than for a C18:2 acid molecule. Bruggen et al. (1998) reported that the lowest isomerization rate is observed for the monoenoic FA. For the formation of geometrical isomers of unsaturated FA to be avoided during deodorization, the temperature in the deodorizer should be 
relatively low and the heating time sufficiently short to minimize isomerization (Wolff, 1994). Refining has the purpose of not only eliminating impurities, but also minimizing trans $F A$ formation (Kellens, 1997). Because the quality variables for refined vegetable oils include the lowest possible content in trans fatty acids, this is more and more important as a contemporary quality criterion (Leon-Camacho et al., 1999; Henon et al., 1999).

\section{CONCLUSIONS}

The results demonstrate an important disparity in the trans FA contents among the studied commercially refined vegetable oils and within each group of oils due to their different unsaturated FA levels and variable industrial refining methods employed. Because of their high levels of monounsaturated $\mathrm{FA}$, refined hazelnut oils contained limited amounts of total trans polyunsaturated FA and also total trans FA. However, other commercially refined vegetable oils with a relatively high total polyunsaturated FA contained considerable amounts of these FA. The obtained results revealed that it is important to be aware of the nutritional quality of refined vegetable oils. As a corollary, deodorization conditions during industrial refining processes should be carefully evaluated in order to prevent the formation of trans FA or to keep their content at a low level in the vegetable oils that are rich in polyunsaturated FA, particularly soybean oils.

\section{ACKNOWLEDGEMENTS}

This work was supported by the Trakya University Scientific Research Projects Fund (Project No. TUBAP-484).

\section{REFERENCES}

Ackman RG, Hooper SN. 1974. Linolenic acid artifacts from the deodorization of oil. J. Am. Oil Chem. Soc. 51, 42-49.

AOCS. 1992. Official Methods and Recommended Practices of the American Oil Chemists' Society, $4^{\text {th }}$ Ed. American Oil Chemists' Society, Champaign, IL. Method Ce 2-66.

Bruggen PC, Duchateau GSMJE, Mooren MMW, Van Oosten HJ. 1998. Precision of low trans fatty acid level determination in refined oils. Results of a collaborative capillary gas-liquid chromatography study. J. Am. Oil Chem. Soc. 75, 483-488.

De Greyt W, Radanyi O, Kellens M, Huyghebaert A. 1996. Contribution of trans fatty acids from vegetable oils and margarines to the Belgian diet. Fett/Lipid 98, 30-33.

Duchateau GSMJE, Van Oosten HJ, Vasconcellos MA. 1996. Analysis of cis and trans fatty acid isomers in hydrogenated and refined vegetable oils by capillary gas-liquid chromatography. J. Am. Oil Chem. Soc. 73, 275-282.
Erickson DR. 1995. Overview of modern soybean processing and links between processes. In: Erickson DR (ed.), Practical Handbook of Soybean Processing and Utilization, pp. 62-64, AOCS Press, Champaign.

FDA. 2003. Food and Drug Administration, food labeling: Trans fatty acids in nutrition labeling, nutrient content claims, and health claims. Fed. Regist. 68, 4143441506.

Ferrari RAP, Schulte E, Esteves W, Bruhl L, Mukherjee KD. 1996. Minor constituents of vegetable oils during industrial processing. J. Am. Oil Chem. Soc. 73, 587592.

García JO, Meza NG, Rodríguez JAN, Quiñónez OD, Galindo HSG, Guerrero JOA, Juárez LAM. 2006. Refining of high oleic safflower oil: effect on the sterols and tocopherols content. Eur. Food Res. Technol. 223, 775-779.

Henon G, Kemeny Z, Recseg K, Zwobada F, Kovari K. 1999. Deodorization of vegetable oils. Part I: Modeling the geometrical isomerization of polyunsaturated fatty acids. J. Am. Oil Chem. Soc. 76, 73-81.

Jawad IM, Kochhar SP, Hudson BJF. 1983. Quality characteristics of physically refined soya bean oil: effects of pre-treatment and processing time and temperature. J. Food Technol. 18, 353-360.

Jung MY, Yoon SH, Min DB 1989. Effects of processing steps on the content of minor compounds and oxidation of soybean oil. J. Am. Oil Chem. Soc. 66, 118-120.

Karaali A. 1985. The effects of refining on the chemical composition of Turkish sunflower seed oil. Fette Seifen Anstrichmittel 87, 112-117.

Kellens M. 1997. Current Developments in Oil Refining Technology. Technical Report, pp.35-48, De SmetBelgium. Antwerp, Belgium.

Kemeny Z, Recseg K, Henon G, Kovari K, Zwobada F. 2001. Deodorization of vegetable oils: Prediction of trans polyunsaturated fatty acid content. J. Am. Oil Chem. Soc. 78, 973-979.

León-Camacho M, Ruíz-Méndez MV, GracianiConstante E. 1999. Isomerization of fatty acids during deodorization and physical refining-stripping with nitrogen. Fett/Lipid 101, 290-294.

Martin CA, Milinsk MC, Visentainer JV, Matsushita M, De-Souza NE. 2007. Trans fatty acid-forming processes in foods: a review. An. Acad. Bras. Cienc. 79, 343-350.

Martin CA, Visentainer JV, Oliveria AN, Oliveria CC, Matsushita M, De-Souza NE. 2008. Fatty acid contents of Brazilian soybean oils with emphasis on trans fatty acids. J. Brazilian Chem. Soc. 19, 117-122.

Matthaus B, Bruhl L. 2003. Quality of cold-pressed edible rapeseed oil in Germany. Nahrung/Food 47, 413-419.

Mayamol, PN, Samuel T, Balachandran C, Sundaresan A, Arumughan C. 2004. Zero-trans shortening using palm stearin and rice bran oil. J. Am. Oil Chem. Soc. 81, 406-413.

Medina-Juárez LA, Gámez MN, Ortega GJ, Noriega RJA, Angulo GO. 2000. Trans fatty acid composition and tocopherol content in vegetable oils produced in Mexico. J. Am. Oil Chem. Soc. 77, 721-724.

Schwarz W. 2000. Formation of trans polyalkenoic fatty acids during vegetable oil refining. Eur. J. Lipid Sci. Technol. 102, 648-649.

Tasan M, Demirci M. 2003. Trans FA in sunflower oil at different step of refining. J. Am. Oil Chem. Soc. 80, 825-828. 
Van Hoed V, Depaemelaere G, Vila Ayala J, Santiwattana P, Verhe R, De Greyt W. 2006. Influence of chemical refining on the major and minor components of rice bran oil. J. Am. Oil Chem. Soc. 83, 315-321.

Wolff RL. 1993. Heat-induced geometrical isomerization of a-linolenic acid: effect of temperature and heating time on the appearance of individual isomers. J. Am. Oil Chem. Soc. 70, 425-430.

Wolff RL. 1992. Trans-polyunsaturated fatty acid in French edible rapeseed and soybean oils. J. Am. Oil Chem. Soc. 69, 106-110.
Wolff RL. 1994. Cis-trans isomerization of octadecatrieonic acids during heating. Study of Pinolenic (cis-5, cis-9, cis-12 18:3) acid geometrical isomers in heated pine seed oil. J. Am. Oil Chem. Soc. 71, 1129-1134.

Zehnder CT. 1995. Deodorization. In: Erickson DR (ed.) Practical Handbook of Soybean Processing and Utilization, pp.240-244, AOCS Press, Champaign.

Recibido: 5/10/10 Aceptado: 10/12/10 